\title{
University-Community Partnerships and Equity in Making
}

\author{
Sagit Betser \\ sbetser@ucdavis.edu \\ Colin Dixon \\ cghdixon@ucdavis.edu \\ Lee Martin \\ leemartin@ucdavis.edu \\ University of California, Davis \\ One Shields Ave. \\ Davis, CA 95616 \\ Richard P. Durán \\ duran@education.ucsb.edu \\ Jasmine K. McBeath \\ kmcbeath@education.ucsb.edu \\ David J. Sañosa \\ dsanosa@education.ucsb.edu \\ Gevirtz Graduate School of Education \\ University of California, Santa Barbara \\ Santa Barbara, CA 93106
}

\author{
Barbara Drucker \\ bdrucker@arts.ucla.edu \\ Hirsch Perlman \\ hirschperlman@sbcglobal.net \\ Casey Reas \\ reas@ucla.edu \\ Ben Refuerzo \\ refuerzo@ucla.edu \\ Aparna Sharma \\ aparnasharma@arts.ucla.edu \\ UCLA School of the Arts \& \\ Architecture \\ Broad Art Center, Suite 8260 \\ Los Angeles. CA 90095
}

\begin{abstract}
In this collection of posters, we add to the community conversation on equity and access in making by considering the work of four UC Links sites. UC Links is a network of university-community partnerships with a long-standing focus on equity.
\end{abstract}

\section{CCS Concepts}

Applied computing $\rightarrow$ Interactive learning environments

\section{Keywords}

Making; the Maker Movement; youth; equity; university community partnerships.

\section{INTRODUCTION}

Making and the maker movement have been heralded as potential change agents in the world of education. Blikstein ${ }^{2}$ argues that giving students access to powerful tools for production can be liberating force. Martin ${ }^{12}$ notes that making typically takes an assetbased, rather than deficit-based, view of learners. Halverson and Sheridan ${ }^{10}$ argue that making can push learning spaces to take expanded, and more equitable, definitions of learning.

Coupled with this enthusiasm, however, is an abiding concern about the lack of attention to equity and diversity within maker education settings. Vossoughi et al. ${ }^{14}$ argue persuasively that making, as represented in the media and by government funding agencies, is commercialized (represented by Maker Media) and pervasively a white, middle-class, male pursuit. As such, it is not

Permission to make digital or hard copies of all or part of this work for personal or classroom use is granted without fee provided that copies are not made or distributed for profit or commercial advantage and that copies bear this notice and the full citation on the first page. Copyrights for components of this work owned by others than the author(s) must be honored. Abstracting with credit is permitted. To copy otherwise, or republish, to post on servers or to redistribute to lists, requires prior specific permission and/or a fee. Request permissions from Permissions@acm.org.

FabLearn '16, October 14 - 16, 2016, Stanford, CA, USA

Copyright is held by the owner/author(s). Publication rights licensed to

ACM.

ACM 978-1-4503-4802-7/16/10 ..\$15.00

DOI: http://dx.doi.org/10.1145/3003397.3003413 well-poised to serve traditionally marginalized groups such as working-class youth and young people of color. Certainly, there are many who hope to broaden participation in making, but too often, Vossoughi et al. ${ }^{14}$ argue, this involves "outreach" efforts that hope to bring making to underserved communities, rather than working to discover and support long-standing maker practices within these communities.

These critiques are of fundamental importance to our community. If we believe in the power of making as a set of educational practices, we must attend to issues of equity and access, and we must go beyond narrow conceptions that focus solely on who participates. In this collection of posters, we add to the community conversation on equity and access in making by considering the work of four UC Links sites. UC Links is a network of universitycommunity partnerships with a long-standing focus on equity.

\section{UC LINKS NETWORK}

UC Links is a network of youth-serving programs, mostly in afterschool time, formed as collaborations between university and community partners. Initiated 20 years ago, UC Links was based on the Fifth Dimension and Clase Mágica programs, which focused on culturally responsive computer activities ${ }^{6}$. Today, there are almost 30 UC Links sites spread around the world, with the majority found in California. UC Links sites have expanded their focus to explore and support broad definitions of literacies and practices.

In these programs, university students take an education course that includes work at a field site. At the field site, they mentor underserved P-12 youth. In class, they share their experiences, read educational research, and engage in inquiry on the nature of learning and literacy at their field sites.

Although UC Links sites are diverse in their foci, they share a commitment to expansive and youth-centered views of what counts as literacy. With shared values of inquiry, teaching, and service, a broad research base, and a long history of collaboration with populations underrepresented in STEM, UC Links is well positioned to examine equity in making. By employing this approach, UC Links sites can "value the resources and capacities of young people who have been historically marginalized in 
making and in STEM, thereby shifting the culture of making to one that is more inclusive"4.

\section{COLLABORATIVE POSTER SESSION}

In the sections that follow, we summarize projects from four UC Links sites. Each site will prepare a separate poster for presentation at the conference, with all focused on issues of equity and access in making. The various sites serve a diverse population of students and provide a variety of analytic perspectives on learning, participation, and equity within making.

\section{WORD CLOUD PROJECT}

\subsection{Project context}

The project was based in a makerspace program at an afterschool Teen Center in Isla Vista, an unincorporated area adjacent to the University of California Santa Barbara populated by approximately 20,000 residents. These include 12,000 transient college students, a small residential professional community, a small homeless population, and a large population of more than 5,000 low-income Latin@ immigrant families whose children are at-risk for completing high school and going to college. ${ }^{3}$ Improving the wellbeing of the Isla Vista community has been a serious issue over the last fifty years, given the disparities in income, formal education, and need for social services of community members. Recently, there has been a new level of university and community concern after a mass shooting tragedy in 2014. In particular, there has been more effort to include Latino families, who have historically been overlooked in the characterization and representation of Isla Vista. With support from the UC Links project and the UCSB administration, the civic engagement project and youth-oriented makerspace were both developed out of an initiative to strengthen university-community ties.

The Word Cloud civic engagement project emerged from a community survey project implemented by a partner project involving UCSB students and a nonprofit specializing in youth empowerment. Teen Center youths polled 300 residents on the well-being of community members and reported on these results at a town hall and community conference. After collecting the survey results, those youths who were also Teen Center makerspace participants worked with the qualitative data on best and worst qualities of Isla Vista and created visual displays in the form of a negative and positive word cloud. As a further step they created an interactive heart-shaped Word Cloud poster made up of electronic circuits and touch capacitance sensors activating sound bites. These circuits used a "plug and play" microprocessor and conductive ink. Participants chose twelve words from the most commonly cited phrases about their town, and linked representative sounds so they played when someone touched each word.

\subsection{Theory and Design}

Critical making is a version of Maker culture that can explicitly address populations underrepresented or undervalued in STEM. Blikstein writes, "Constructive, expressive technology makes it possible to further Freire's agenda of emancipation, perhaps as powerfully as with language and literacy"2. The critical making approach is especially powerful for marginalized youth because it can forge connections and support STEM-underrepresented youth's enactment as "change agents" in their communities4. This is particularly relevant for girls, who cite helping or giving as their biggest motivation for making, and tend to pursue projects that benefit the community ${ }^{15}$. Girls appear to thrive on the collaborative, artistic, and community-oriented aspects of making ${ }^{15}$, but more research needs to be done to explore how these aspects come into play, and what meaning they hold for the participants and their communities.

Tracing dialogue and multimodal practices across time allowed us to examine goal-oriented tool mediation in relation to placemaking. We used the mobilities of learning framework to further explore learning across different domains. With roots in sociocultural theory, the framework is about the interconnected movement of people, places, and things, and the effect on learning spaces and social practices. ${ }^{4}$ Learning is viewed in relation to time, place, and across networks ${ }^{11}$ where there is both horizontal and vertical learning, crossing between different spaces in youths' lives $^{9}$.

\subsection{Data}

Preliminary data analysis reveal that there were many affordances for creating meaning by youths that critically reflected their understanding and analysis of the social life of the Isla Vista community. Students reported that they felt proud in designing and implementing the Word Cloud project and in the positive reception from community adults responding to their final project presentation and finished Word Cloud artifact. Data showed that youths also chose different project roles for themselves, but were fluid so that everyone contributed in some way to all parts of the project. Youths expressed awareness that their project involved both technological and artistic expertise, yet no one person or small group did all the work associated with either role. Knowledge and responsibility was distributed across participants, so that youths were able to collaborate and yet claim their own stake in the project.

Data also revealed important challenges faced by project participants. Participants expressed pressures of time and multiple players of complex teamwork that added stress, and appeared to increase frustration levels. Multiple times frustration arose from not being able to transfer information and knowledge from one medium to another, such as from the digital to the physical Word Cloud, or effectively convey the emotion behind the word with the sound chosen. The sense of audience appeared to add another layer, and possibly more weight, to their creation process. There was also the challenge of the youth maintaining ownership over the project with many different people and interests involved with staff, mentors, and community partners.

\section{ST. GEORGE CENTER 5.1 Project context}

The St. George Family Youth Center (SGFYC), in Isla Vista, CA is a community center which during after-school hours predominately serves local adolescent Latino/Latina youth, with the help of volunteers and staff which includes members of the community and local high school, undergraduate, and graduate students from the University of California, Santa Barbara that are part of the UC Links network. The informal, diverse, and dynamic environment consists of youths freely engaging in various activities with their peers, volunteers, and staff members. The youths primarily come from low income immigrant families, and the site provides them with much-needed access to technology in the form of modern desktop computers, which are typically used for homework or entertainment. The availability of these computers provides a base for interfacing with other kinds of digital devices, such as the Arduino microcontroller-based platform. Arduino is a low-cost programmable "physical computing platform" that has the capacity to utilize an array of physical sensors and the ability to control physical devices. The project involves teaching and working with a group of SGFYC members and volunteers in the construction and understanding of potentially interactive electronic objects which can be displayed to a community of peers. 


\subsection{Theory/Design}

Engagement in Arduino projects is an instance of "making" as conceived by members of the Maker movement which draws on constructionist theories in placing the creation of meaningful artifacts as a key mediator of learning, typically positioned within a community setting ${ }^{10}$.

Learning by doing can also be understood through a situated cognition perspective, which Gee claims "stresses knowledge as tied to activity and experiences in the world before knowledge as facts and information"8. Gee also ties this perspective to the idea of multiple literacies, including "digital literacies", which give rise to meaning in social, cultural, historical and institutionally defined ways ${ }^{8}$. The complexity of navigating multiple literacies can present many challenges to learners, especially when the digital tools to be used were not strictly designed for the purpose of connected learning that integrates many different forms of learning into ongoing repertoires of practice extending beyond solution of immediate technical problems ${ }^{1}$. In particular in more extended forms of learning, learners can introduce their own literacies, drawing from their lived experiences and "funds of knowledge"13, or integrate these new digital literacies with their own cultural practices $^{7}$, which is especially relevant for learners from minority backgrounds.

Our exploratory efforts towards implementing a connected learning vision of Arduino projects are in a preliminary mode in one of our SGFYC youth teams concentrating on microprocessors. Due to the informal nature of the setting, the facilitators deliberately have no set curriculum, and we have so far attempted to teach the nature of each of the components of the Arduino toolkit. The facilitators put effort, when possible, into maintaining the learners' self-direction by fielding input, ideas, and motivations. As we proceed we will introduce more complex microprocessor based projects with complex connected learning goals.

\subsection{Illustrative Example}

An episode that illustrates the kinds of literacies at play takes place during a lesson on connecting and controlling multiple LEDs to an Arduino with a group of boys at the site. They were exploring how to turn the lights on and off in a particular sequence. The older boys were able to guide the younger boys (and each other) towards meaningful actions, just as the facilitators guided them.

At this stage, the boys had previous experience with the tools but were still struggling with navigating their complicated symbolic systems. The boys often found themselves placing wires in locations where they could not form connections. When entering computer code, the younger boys had difficulty typing and interacting with the text itself. Understanding the programming language, however, is even less forgiving to novices in respect to the number of conventions and rules involved in performing meaningful actions.

In the process of designing and planning the boys were more readily able to draw from their experiences and abilities. One of the boys spontaneously employed a strategy involving gesture to map out the sequence of the three LEDs. He placed the ends of three of his fingers on the table, each finger representing a light, and tapped his fingers in the order he was proposing. From an embodied cognition perspective, his strategy could be interpreted as a way of externalizing his thinking in his own physical actions, thinking "through his fingers". This was a simple way of mapping the plan and also served as an effective communication to the facilitator. Many of the older boys play with LED lights in their free time, in an artistic activity known as "gloving". When they succeed in turning on the LEDs, they wonder if they can get them in similar "modes" of blinking and color changes as their own lights.

\section{FORM ACADEMY}

\subsection{Project description}

The FORM Academy at UCLA in the School of the Arts and Architecture is the first FREE summer interdisciplinary arts studio program for inner city high school students interested in expanding their understanding of the world of art and in experiencing university life - with the goals being to broaden understanding of the practice of contemporary art, emphasizing its relevance and connection to other disciplines and contemporary life, and to encourage participants to feel comfortable in a university setting and to seek higher education, be it in the arts or otherwise.

FORM is the first collaboration between five tenured professors representing all departments within our school including: Barbara Drucker, Department of Art; Hirsch Perlman, Department of Art; Casey Reas, Department of Design Media Arts; Ben Refuerzo, Department of Architecture and Urban Design; and Aparna Sharma, Department of World Arts and Cultures/Dance.

Additionally, five recent graduate students from all departments were selected as "mentors" to develop and lead the studio sessions and campus tours, which comprise the main components of this week-long program. Faculty members will work alongside the mentors during the studio sessions to further facilitate discussion, critical thinking and deepen understanding of the creative process.

\subsection{Pedagogical Design}

Most days the FORM schedule includes a substantial amount of studio work and a campus tour or introduction to another program. A summary of the tentative schedule is included below:

- Monday - Orientation, Icebreaker, Studio, Lunch, Explore Campus

- $\quad$ Tuesday - Studio, Lunch, Studio

- Wednesday - Studio, Lunch, Fowler Museum \& Engineering Tours

- $\quad$ Thursday - Studio, Lunch, Studio, CAP \& Royce Hall Tour

- $\quad$ Friday - Studio, Lunch, Hammer Museum \& Campus Tour

- $\quad$ Saturday - Studio Wrap Up, Lunch, Presentation of Creative Work

Dreaming Identity is the conceptual theme weaving together all studio sessions, with each emphasizing a specific theme and activity defined by the mentor, including the following examples:

\section{Scaling the Imagination}

Architects do not just build buildings, they make places as well. When left to imagination a place can be more than just the form of a box and the space within it. What kind of place can you make using everyday materials.

\section{Nonhuman Costume Mashup}

What does a costume look like that doesn't start from the human body? Think of buildings and birds, machines and music, words and wolves. Make a costume - a wearable piece of art that doesn't mimic the human body.

\section{Building Outside and Inside}


How can structures protect and comfort? Take 15 minutes to share the masks and costumes you worked on in previous sessions with your group. Brainstorm what the inside and outside of a building to house these characters would look like. Use a corner of the studio and as a group create a space that is shaped as much from its inhabitants (your masks and costumed creatures) as it is from the world those inhabitants live in.

A call for applications was sent to arts education colleagues, high school counselors and classroom teachers in Title I public high schools across LA County resulting in the submission of 61 applications from a diverse range of students representing 21 high schools in the county. The application requested standard contact information in addition to a personal statement describing why the applicant would be a good fit for the FORM Academy. After some discussion it was decided to accept participants according to when they applied - i.e., a first come, first served approach, rather than trying to interpret the limited information on the application form. Students were accepted from grades 9 through 12 this first time around, and we plan to see how this range in age and experience works out, with the intention to modify the cohort parameters next year, if needed.

The FORM initiative is viewed by the School as an important aspect of its community outreach activities and therefore is being partially supported by the Dean's Office. It is also being funded by private donations and other departments in the School. Participants will be introduced to a range of arts disciplines, with the unifying emphasis being placed on creative process, making, invention, imagination and exploration, rather than on discipline-based art works with a product orientation. Most of the students selected for this program have expressed excitement about being on the UCLA campus, some for the first time, and about the range of arts experiences offered. They are also excited about being able to interact with the university professors and recent graduates, all practicing artists, in addition to getting to know peers from other schools across the city.

Pre/post evaluation forms will be filled out by the student participants, and upon completion of the FORM Academy, faculty and mentors will evaluate the overall success of the program and discuss its components and format for the next year.

\section{BETA LAB}

\subsection{Program Description}

The program, based out of UC Davis, took place in a diverse public charter high school in a city in Northern California. The goal of the program was to create a makerspace to support high school students in creating projects of their own choosing. The school has an internship model, where students spend two school days per week at on off-campus internship based on students' interest. For our program, students came to work in the makerspace one day per week, in lieu of one of their internship days. The space was "open" one school day per week, for the duration of the school day, throughout the school year (holidays and special school events excepted). The makerspace itself was a "pop-up" one - for each weekly session, the project team arrived with their mobile makerspace van and, together with the students, transferred the tools and materials from the van to the school's science lab, turning it into a makerspace for the day.

For the first few weeks of the school year, project leads offered introductory workshops on core tool sets like sewing, electronics, and laser cutting, and students were able to sign up for areas of interest. After this introductory period, the space was run as an open makerspace, where students exercised significant autonomy in choosing what to work on, what to learn, and generally how to spend their time. Facilitators' worked to provide resources, help students move their thinking forward, encourage reflection, and help create a physically and emotionally safe space in which students could experiment and design using new tools and materials. A core commitment of the space was to take students' ideas, experiences, and interests seriously, and support students in expanding their thinking and bring their ideas to fruition.

Participants at the high school included fourteen tenth and eleventh graders ( 8 boys, 5 girls and 1 gender fluid). Participants from the university included eight undergraduate students who participated in the program as mentors (some stayed the whole year, and some for one quarter) from a variety of programs at the university. These undergraduates were concurrently enrolled in an education course that incorporated both classroom meetings and mentoring work at the high school makerspace. Course meetings were once a week for two hours and included activities to support the mentoring experience and understanding of learning within a making environment.

\subsection{Analytic Focus}

This poster will consider how participating in a makerspace environment and working with high school students challenged undergraduate students' views of mentoring, of themselves as mentors, and of "what counts" as learning. Data include undergraduates' class discussions (audio recorded) and weekly reflections (submitted in paper), and analysis focuses on changes in perspectives and discourse throughout the year.

Preliminary analyses shows that undergraduates found this experience to be substantially different from their previous mentoring experiences, both in formal and informal settings. The difference stemmed mainly from the high school students' autonomy in the space, where their decisions drove next steps on projects, rather than an external curriculum. This new context for mentoring led the undergraduate students to report during class discussions and reflection papers on many moments of frustration and feelings of "being stuck" as mentors.

\subsection{Illustrative Example}

One of the undergraduates, Amelia, expressed her frustration working with a high school student, Victor, on his project to design a letter "T" for a sign he was making for the space. In a reflection, she reported, "I worked with Victor on the Beta Booth letters. This was far more frustrating than I anticipated... It seems to take more effort to get through to Victor than the other students." She further reported that all her attempts to help him think of his design were unsuccessful - he did not showing any sign of engagement. Therefore, Amelia gave up and decided to work on her own project (undergraduates were encouraged to have their own projects, as a way to position themselves as co-learners in the space). This was her description of what happened next:

I started working on what I had planned to be my project for the day. I had hoped to design a dog tag for my new dog, Link. I wanted it to be a simple dog bone design with "Link" etched into it, and maybe a design of Link's sword from The Legend of Zelda. Victor became really interested in my project, so much so that he stopped what he was doing and started making suggestions and drawing designs for what I was working on. As terrible as it is, this actually really frustrated me. I was trying to keep him focused on his thing, and I was trying to work on my thing by myself - neither of these things was being 


\section{accomplished... I was very frustrated by Victor for "interfering" with my project.}

When Amelia shared her experience during class, the instructor asked if she knew what Victor did later that session. She did not know, as she had left early that day. The class told her that Victor finally worked on his "T" design and was actually very much engaged in making his " $T$ " design based on Link's sword.

Later, in her reflection on her mentoring, Amelia described this experience very differently. She described her interaction as "good" and said she realized that working next to someone can also be a "mentor move." She also tried to understand Victor change's in participation:

He is smart, and he wants to make things, but he doesn't know how to get started, and he can be difficult to work with. The day I had this good interaction with him was actually a really frustrating day... I realized that this was a really good interaction... I also realized, that by simply sitting with Victor and working on my own thing, I helped him. He found a design for his project, and was able to move forward with it after I left. Through this interaction and an interaction Victor shared with [another mentor], we were able to see that Victor is more comfortable helping other people than working on his own project. When Victor is helping someone else, ideas come flowing out of him, but when Victor works alone, the ideas are short lived.

This example shows one of the ways in which student autonomy a feature typical for a makerspace but distinctive in the undergraduates experiences in educational settings - can occasion a shift in perspective on what it means to learn, and what it means to mentor.

\section{CONCLUSION}

Across these papers, we see a variety of approaches to creating maker experiences that are deeply focused around building from young people's ideas, experiences, and funds of knowledge. We believe that these sites make a significant contribution to the much needed discourse on models of equity and access in making.

\section{ACKNOWLEDGMENTS}

All projects are supported by grants from UC Links (a program of UC Office of the President, http://uclinks.berkeley.edu/) to individual campuses. Additional funding for UCSB's Maker Project at the St. George Family Youth Center was provided by an award from the UCSB Chancellor's Coordinating Committee on Isla Vista. UCSB work is also supported by the National Science Foundation Graduate Research Fellowship under Grant No. DGE 1144085. Research from UC Davis Beta Lab site is also supported by the National Science Foundation under Grant No. EEC1351605 .

\section{REFERENCES}

[1] Blikstein, P. (2013). Gears of our childhood: constructionist toolkits, robotics, and physical computing, past and future. In Proceedings of the 12th International Conference on Interaction Design and Children (pp. 173-182). ACM.

[2] Blikstein, P. 2008. Travels in Troy with Freire: technology as an agent for emancipation. In Social Justice Education for
Teachers: Paulo Freire and the Possible Dream, P. Noguera and C. A. Torres, Eds. Sense. Rotterdam, Netherlands, 205244.

[3] Burns, M. 2016. Is Isla Vista Growing Up? The Independent Available at:

http://www.independent.com/news/2016/mar/03/isla-vistagrowing/

[4] Calabrese Barton, A., Tan, E., and Greenberg, D. 2016. The Makerspace Movement: Sites of possibilities for equitable opportunities to engage underrepresented youth in STEM. Teachers College Record. To appear.

[5] Cavallo, D., Blikstein, P., Sipitakiat, A., Basu, A., Camargo, A., de Deus Lopes, R., and Cavallo, A. 2004. The city that we want: generative themes, constructionist technologies and school/social change. In Proceedings of the IEEE International Conference on Advanced Learning Technologies. 1034-1038. DOI $=10.1109 /$ ICALT.2004.1357744

[6] Cole, M., \& Distributive Literacy Consortium. (2006). The fifth dimension: An after-school program built on diversity. Russell Sage Foundation.

[7] Eglash, R., Gilbert, J. E., \& Foster, E. (2013). Toward culturally responsive computing education. Communications of the ACM, 56(7), 33-36.

[8] Gee, J. P. (2010). A situated-sociocultural approach to literacy and technology. The new literacies: Multiple perspectives on research and practice, 165-193.

[9] Gutiérrez, K. 2008. Developing a sociocritical literacy in the Third Space. Read Res Quart. 43,2. 148-164. DOI $=10.1598 /$ RRQ.43.2.3

[10] Halverson, E. R., \& Sheridan, K. (2014). The maker movement in education. Harvard Educational Review, 84(4), 495-504.

[11] Leander, K.M., Phillips, N.C., and Taylor, K. H. 2012. The changing social spaces of learning: Mapping new mobilities. Rev Educ Res. 34,1, 329-394. DOI= $10.3102 / 0091732 X 09358129$

[12] Martin, L. (2015). The promise of the Maker Movement for education. Journal of Pre-College Engineering Education Research (J-PEER), 5(1), 30-39. http://dx.doi.org/10.7771/2157-9288.1099

[13] Moll, L. C., Amanti, C., Neff, D., \& Gonzalez, N. (1992). Funds of knowledge for teaching: Using a qualitative approach to connect homes and classrooms. Theory into practice, 31(2), 132-141.

[14] Vossoughi, S., Hooper, P. K., \& Escudé, M. (2016). Making Through the Lens of Culture and Power: Toward Transformative Visions for Educational Equity. Harvard Educational Review, 86(2), 206-232.

[15] Wittemyer, R., McAllister, B., Faulkner, S., McClard, A., \& Gill, K. 2014. MakeHers: Engaging girls and women in technology through making, creating, and inventing. Technical Report. Intel Corporation. 